\title{
CONTRIBUCIÓN AL REGISTRO HISTÓRICO DE ACTIVIDAD DE LOS VOLCANES CHILES Y CERRO NEGRO (FRONTERA COLOMBO-ECUATORIANA)
}

\author{
María Luisa Monsalve B. ${ }^{1}$; Carlos Andrés Laverde C. ${ }^{2}$
}

DOI: http://dx.doi.org/10.18273/revbol.v38n4-2016004 (c) (i)

Forma de citar: Monsalve, M.L., y Laverde, C.A. 2016. Contribución al registro de actividad de los volcanes Chiles y Cerro Negro (frontera colombo-ecuatoriana). Boletín de Geología, 38(4): 61-78.

\section{RESUMEN}

La recopilación documental de información histórica sobre la actividad de los volcanes Chiles $\left(0^{\circ} 49^{\prime}\right.$ $\mathrm{N}$ y $77^{\circ} 56^{\prime} \mathrm{W}, 4.748$ m.s.n.m.) y Cerro Negro ( $0^{\circ} 46^{\prime} \mathrm{N}$ y $77^{\circ} 57^{\prime} \mathrm{W}, 4.470$ m.s.n.m.), en la frontera colombo-ecuatoriana, permite interpretar que estos volcanes han presentado signos de actividad eruptiva menor, posiblemente desde épocas prehispánicas, ya que a inicios de la época de la colonia el Chiles era reconocido como volcán, a pesar de encontrarse en un ámbito geográfico aislado. Hacia la segunda mitad del siglo XIX, el volcán Chiles presentó una actividad fumarólica intensa, la cual pudo estar asociada a eventos eruptivos menores, ocurridos posiblemente entre 1860 y 1869 , focalizados en el flanco sur del volcán; en este mismo período se reportan manifestaciones hidrotermales y fumarólicas incipientes al interior del anfiteatro del volcán Cerro Negro y posible actividad eruptiva hacia comienzos del siglo XX, mientras que la actividad fumarólica en Chiles para entonces había desaparecido. Entre 1923 y 1924, se registró una sismicidad significativa (incluyendo un evento de profundidad superficial y magnitud 6 en la escala de Richter) que en su momento fue asociada a erupciones del volcán Chiles. La falta de datos más precisos sobre la actividad eruptiva de estos volcanes se debe posiblemente a la escasa población en la zona que pudiera hacer reportes sobre dicha actividad, a que correspondiera a eventos eruptivos menores y al hecho de considerarse, algunas veces, a los dos centros volcánicos como un solo volcán.

Palabras clave: Volcán Chiles, volcán Cerro Negro, actividad histórica.

\section{HISTORICAL ACTIVITY RECORD OF CHILES AND CERRO NEGRO VOLCANOES (COLOMBIAN-ECUADORIAN BORDER)}

\begin{abstract}
Documentary collection of historical information about the activity of the Chiles $\left(0^{\circ} 49^{\prime} \mathrm{N}\right.$ and $\left.77^{\circ} 56^{\prime} \mathrm{W}\right)$ and Cerro Negro volcanoes $\left(0^{\circ} 46^{\prime} \mathrm{N}\right.$ and $\left.77^{\circ} 57^{\prime} \mathrm{W}\right)$, on the Colombian-Ecuadorian border allows us to interpret that Chiles was active in pre-Hispanic times, since during colonial times it was already recognized as a volcano. By the middle of XIX century, Chiles volcano presented an intense fumarolic activity possibly related to minor eruptive events that could have occurred between 1860 and 1869, which were focused towards the southern sector of the volcano. Hydrothermal and incipient fumarole activity into the amphitheater of Cerro Negro volcano is reported by 1870 , and eruptive activity at the beginning of XX century, while the fumarolic activity in Chiles had disappeared. Later, between 1923 and 1924, a significant seismicity was recorded (including an event of shallow depth and magnitude 6 on the Richter scale) which, in turn, was associated with Chiles volcano eruptive activity. The lack of more precise data on the eruptive activity of these volcanoes is possibly due to the minor eruptive activity, to the sparse population in the area and to the notion that the two volcanoes were considered as one.
\end{abstract}

Keywords: Chiles Volcano, Cerro Negro volcano, historical activity.

\footnotetext{
${ }^{1}$ Servicio Geológico Colombiano, Dirección de Geociencias Básicas, mmonsalve@sgc.gov.co

${ }^{2}$ Servicio Geológico Colombiano, Dirección de Geoamenazas, claverde@sgc.gov.co
} 


\section{INTRODUCCIÓN}

La recopilación y análisis de los reportes sobre la actividad histórica de los volcanes es un aporte fundamental al conocimiento de su comportamiento eruptivo, de los efectos en sus áreas de influencia, así como de la respuesta, en su momento, de habitantes y tomadores de decisiones. Dicho conocimiento permitirá un mejor entendimiento del volcán en caso de reactivación y la formulación de escenarios eruptivos para ser integrados en los programas de gestión de riesgo volcánico.

Los primeros trabajos sistemáticos de recopilación de actividad de los volcanes de Colombia son los de Hantke and Parodi (1966), pero es el padre Jesús Emilio Ramírez (1975) quien hace un valioso aporte a la vulcanología, transcribiendo textos donde se reporta la actividad de varios de los volcanes colombianos. Más recientemente, Espinosa $(2001 ; 2011)$ presenta los trabajos más completos sobre el tema, complementando e interpretando esta información histórica.

En este trabajo se presenta la recopilación e interpretación de datos sobre la actividad de los volcanes Chiles $\left(0^{\circ} 49^{\prime} \mathrm{N}, 77^{\circ} 56^{\prime} \mathrm{W}, 4.748\right.$ m.s.n.m.) y Cerro Negro $\left(0^{\circ} 46^{\prime} \mathrm{N}, 77^{\circ} 57^{\prime} \mathrm{W}, 4.470\right.$ m.s.n.m.), que conforman el Complejo Volcánico Chiles - Cerro Negro $(\mathrm{CVChCN})$ localizado en la frontera ColomboEcuatoriana (FIGURA 1).

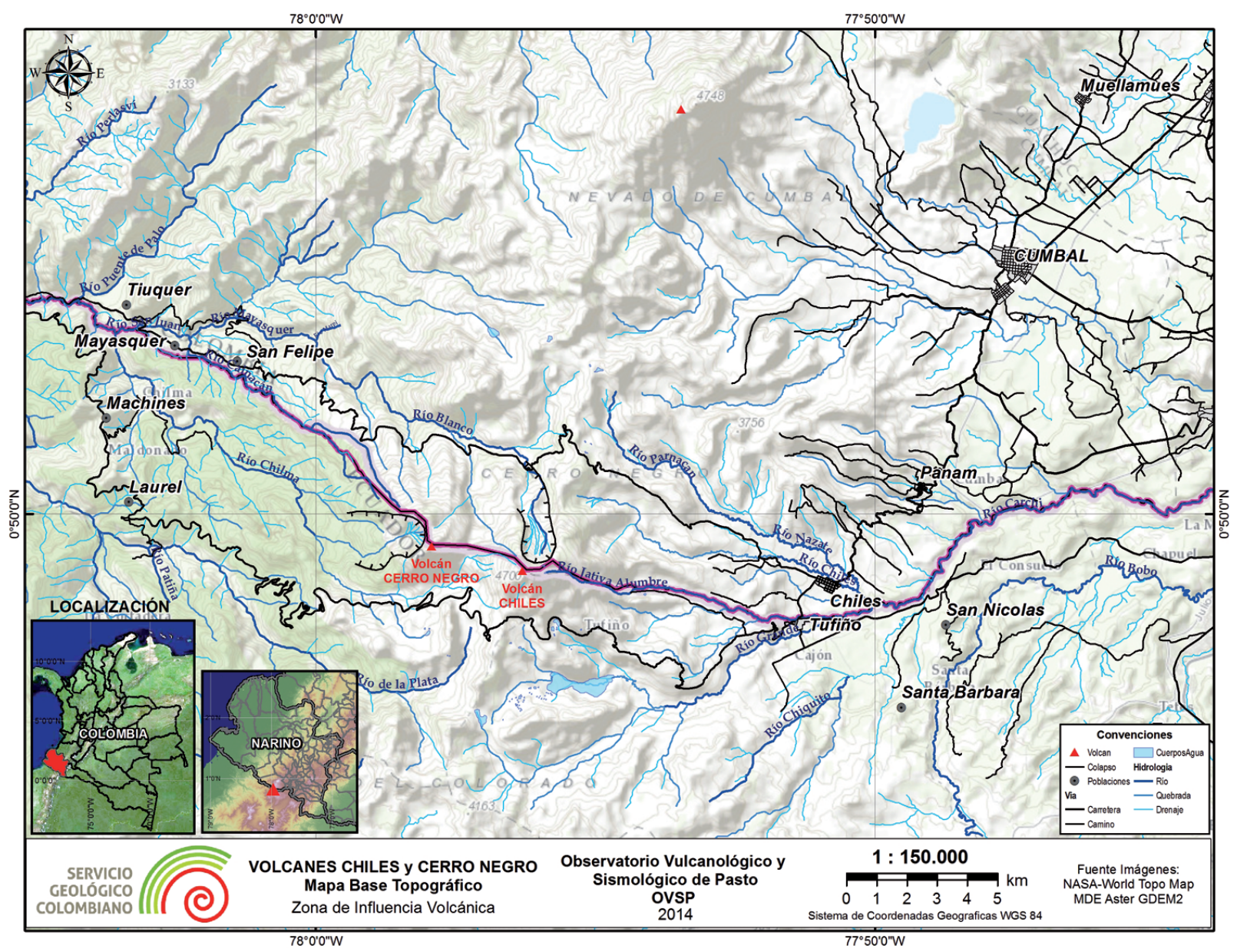

FIGURA 1. Localización del Complejo Volcánico Chiles - Cerro Negro.

\section{ANTECEDENTES}

Desde inicios del 2013, en la zona del CVChCN se comenzaron a registrar por parte del Instituto Geofísico de la Escuela Politécnica Nacional (IGEPN) del Ecuador y del Observatorio Vulcanológico y
Sismológico de Pasto (OVSPasto) del Servicio Geológico Colombiano (SGC), sismos denominados "volcano-tectónicos" (asociados a fracturamiento al interior del sistema volcánico), algunos de ellos con magnitudes entre 3 y 5,6, sentidos por la población en la zona. Adicionalmente, se tienen registro de 
sismos de origen volcánico, deformación y algunos cambios en las fuentes termales, como fluctuaciones en $\mathrm{pH}$ y temperatura, aumento de concentraciones de $\mathrm{CO}_{2}$, salida de Azufre elemental, entre otros (Servicio Geológico Colombiano, 2014; Burbano y Valencia, 2014). Esta actividad indicaría la presencia de material magmático en niveles considerados como superficiales a través de un proceso de intrusión magmática, sugiriendo la reactivación en el complejo volcánico (Ruiz et al., 2014; Torres et al., 2015a, 2015b).

Dada esta situación, el SGC y el IGEPN encaminaron esfuerzos conjuntos con el fin de ampliar la red de monitoreo de estos volcanes y actualizar los mapas de amenaza volcánica existentes (Cortés y Calvache, 1997). Como parte de este último proceso, se inició una recopilación sobre la actividad histórica de Chiles y Cerro Negro, con el fin de obtener datos que complementen el conocimiento que se tiene sobre su actividad eruptiva y su comportamiento actual.

\section{ESTUDIOS ANTERIORES}

En Hantke and Parodi (1966) se encuentran reseñas sobre la actividad del volcán Cerro Negro, teniendo como principal referencia la visita de Reiss y Stübel en el año de 1869 , mientras que describen al volcán Chiles como extinto. Ramírez (1975) compila los reportes sobre erupciones históricas de los volcanes de Colombia y describe de una manera general a los volcanes Chiles y Cerro Negro, como se transcribe a continuación: “...Sigue el Chiles (Lat. $0^{\circ} 54$ 'N. Long. $77^{\circ} 53^{\prime} \mathrm{W} ., 4.470$ metros) en la frontera con el Ecuador, con su monte de nieve y hielo, y con una gran caldera sin señales de actividad en su parte inferior.". Luego añade: "El último volcán de Colombia es el Cerro de Mayasquer (Lat. $0^{\circ} 48^{\prime} \mathrm{N}$. $77^{\circ} 57^{\prime} \mathrm{W}$.) que no alcanza la nieve perpetua, 4.470 metros y su cráter se inclina hacia el Chiles, en la parte occidental. Estos dos últimos volcanes están unidos por una meseta a manera de silla llamada de las Cruces. El Cerro Negro de Mayasquer es un cono truncado estratificado, compuesto por capas de lava y material piroclástico arrojado por un único cráter central.".

Este autor, al hacer el resumen de la actividad de los volcanes de Colombia, incluye al Cerro Negro de Mayasquer, anotando que está en el grupo de los "volcanes con magma o erupciones freáticas conocidas" (FIGURA 2A). Pero en el mapa de localización que denomina "zona volcánica terciaria" es Chiles el que está incluido dentro de este grupo (FIGURA 2B).
A

$\begin{array}{rlll}1 & \text { O } & \text { Mesa Nevada de Herveo } & 15.1-1 \\ 2 & \text { o } & \text { Ruiz } & 15.1-2 \\ 3 & \text { o } & \text { Tolima } & 15.1-3 \\ 4 & \text { O } & \text { Machín } & 15.1-4 \\ 5 & \text { O } & \text { Huila } & 15.1-5 \\ 6 & \text { o } & \text { Puracé } & 15.1-6 \\ 7 & \text { o } & \text { Doña Juana } & 15.1-7 \\ 8 & \text { o } & \text { Galeras } & 15.1-8 \\ 9 & \text { O } & \text { Azufral } & 15.1-9 \\ 10 & \text { o } & \text { Cumbal } & 15.1-10 \\ 11 & \text { o Cerro Negro Mayasquer } & 15.1-11\end{array}$

- Volcanes con magma o erupciones freáticas conocidas.

- Volcanes en estado fumarólico.

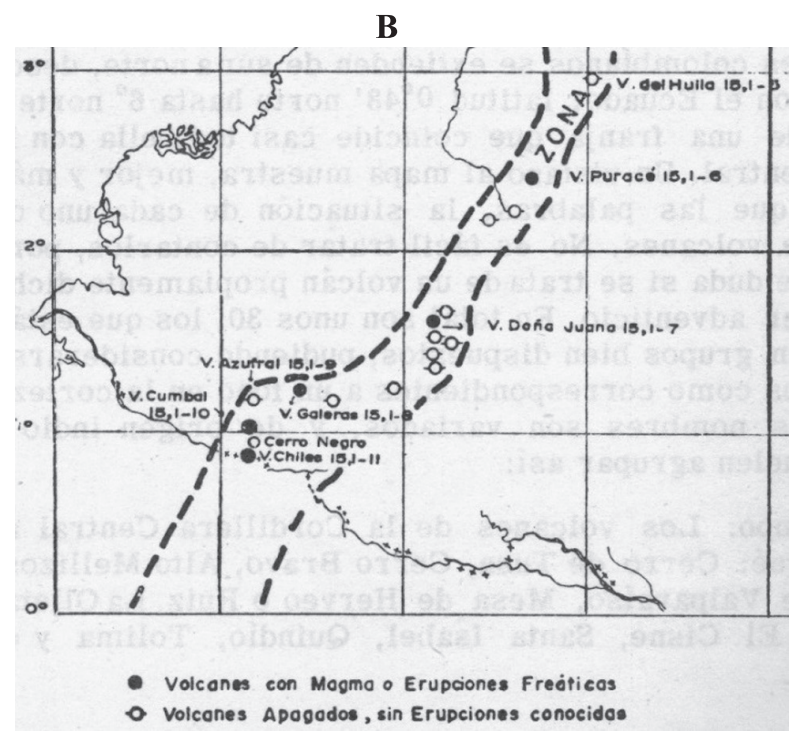

FIGURA 2. A. Resumen de la actividad de los volcanes de Colombia según Ramírez (1975, pág. 55). B. Parte del mapa de localización de los volcanes, mostrando los del SW, grupo al cual pertenecen Chiles y Cerro Negro, indicando al volcán Chiles como activo (Ramírez, 1975, pág. 34).

En la memoria explicativa de la primera versión del mapa de amenaza de los volcanes Chiles y Cerro Negro se incluyen los resultados de la investigación llevada a cabo por la Fundación para la Investigación y el Desarrollo Cultural de Nariño - FINCIC (1996, en: Cortés y Calvache, 1997), sobre la actividad histórica de estos volcanes, realizada para complementar los estudios de evaluación de amenaza volcánica. En este documento, la principal reseña sobre la actividad del volcán Chiles es tomada de trabajos de Ignacio Rodríguez Guerrero del año 1959 (en Cortés y Calvache, 1997), cuya transcripción es la siguiente: "El volcán Chiles en la frontera colombo-ecuatoriana, cuyo cráter expide por 15 bocas humo, ceniza y vapores sulfúricos, produciendo con frecuencia fuertes bramidos, ha sido estudiado por numerosos geólogos nacionales $y$ extranjeros...". Desafortunadamente, no se hace referencia de la fuente original de la transcripción, ni el año en que se llevó a cabo la observación. 
Espinosa (2011), en su obra "Erupciones Históricas de los volcanes Colombianos. 1500 - 2000", afirma que "El volcán Chiles no es mencionado por compiladores anteriores" y que "Las pocas referencias sobre su actividad histórica están relacionadas con los sismos que en la segunda mitad del siglo XIX y en la primera mitad del siglo XX afectaron gravemente el sur de Colombia y el norte del Ecuador.". Este autor hace una importante recopilación de descripciones, relatos y noticias relacionados con la posible actividad del volcán Chiles, a raíz de los sismos ocurridos en 1923 en la zona.

\section{METODOLOGÍA}

Se llevó a cabo la recopilación e interpretación de documentos sobre actividad histórica de los volcanes de Colombia y Ecuador, gran parte de ellos obtenidos en fondos documentales en línea. Inicialmente se consultaron las recopilaciones documentales existentes sobre actividad histórica de volcanes colombianos (Hantke and Parodi, 1966; Ramírez, 1975; Espinosa, 2001, 2011); luego, se consultaron fuentes bibliográficas, inicialmente a través de fondos documentales físicos y en línea institucionales del SGC (biblioteca del Observatorio Vulcanológico y Sismológico de Pasto; Sistema de información técnico-científica - SICAT). No obstante, gran parte de la nueva información encontrada, como un aporte al conocimiento sobre la actividad del CVChCN, provino de fondos documentales en línea, consultados a través de la Internet, encontrándose, en algunos casos fuentes primarias. Adicionalmente, se estableció contacto, vía telefónica y por correo electrónico, con el historiador ecuatoriano Luis Alberto Ibarra.

Con la información compilada se procedió a revisar cuidadosamente estos documentos, haciendo un análisis comparativo de los datos aportados por las diferentes fuentes, que condujeron a la interpretación aquí presentada.

\section{LAS PRIMERAS DESCRIPCIONES}

Los primeros indicios del reconocimiento del Chiles como un volcán activo se remontan a épocas prehispánicas. Delgado (2004), refiriéndose a los orígenes (período Paleoindio) de la cultura Pasto, afirma: "Los primeros vestigios Protopastos [...] parten de la leyenda de Embilput (hombre nacido del [volcán] Chiles en la laguna Voladero) y Embilquer (mujer nacida de la Laguna del Cumbal), que dan inicio a la raza Pasto [...] esos vestigios se remontan probablemente al período Precerámico.". Varios autores, entre ellos, Rosero (1999; 2006), Ibarra y Romero (2011), Ibarra (2003) y Pérez y Rosero (2013), aportan detalles respecto a la reconstrucción, basada principalmente en la tradición oral de la leyenda de Embilput y Embilquer. Pérez y Rosero (2013), transcriben la narración que el historiador ecuatoriano Luis Alberto Ibarra hace de esta leyenda: "La bella geografía de lo que antiguamente era la gran Nación Pasto, con un colorido verdoso y un horizonte azul observando al fondo a dos colosos que son los guardianes de la frontera. El cerro Chiles era considerado el varón, el macho fuerte, un especie de dios, su presencia imponía respeto, fortaleza, y el cerro Cumbal era la hembra que reflejaba ternura unión y fertilidad ambos cerros eran hijos del sol pasto y por lo tanto eran los amos de la cordillera, sus entrañas eran ardientes y brotaban lava hacia las partes bajas. cambiando cada día la apariencia geográfica, asi la lava del Chiles llego hasta la laguna del voladero y la lava del Cumbal a la laguna del mismo nombre cada cerro dio un hijo que broto de las aguas, llenos de energía que rugía del fondo de los volcanes así del voladero nació el barón llamado Embilput y de la laguna el Cumbal surgió una hermosa doncella que se llamaría Embilquer que significaba luz, los dos seres Pastos salieron de las profundas aguas heladas en 10 meses solares, la pareja se enamoró y tenían la misión de fecundar y poblar toda las regiones altas de la montaña formando una gran nación que perdure su cultura. Embilput y Embilquer envejecieron y se cumplió la misión sagrada. Los dos ancianos volvieron a las aguas sumergiéndose para salir por el cráter de los volcanes transformados en dos fuertes cóndores que con su vuelo cuidaran siempre a la gran nación Pasto."

Si bien los flujos de "lava" mencionados en este relato son difícilmente corroborables, desde el punto de vista del registro geológico, y aun reconociendo que estas narraciones, basadas en la tradición oral y en el imaginario de los pueblos indígenas, mezclan la realidad con elementos mitológicos, este tipo de relatos evidencia que las comunidades Pastos, habitantes de la zona del CVChCN en tiempos precolombinos, reconocían al Chiles y al Cumbal como volcanes activos, motivados probablemente por manifestaciones que observaron de su actividad y que alimentaron su imaginario. Cabe anotar que autores como Delgado (2004) sitúan al período Pre-Cerámico en la región colombo-ecuatoriana, entre 10.000 A.C. y 3.550 A.C.

Luego de la llegada de los españoles a nuestra América, la primera alusión encontrada sobre Chiles y Cerro 
Negro está relacionada con las primeras décadas de la colonización, según transcripción de Tapia et al. (2011): “...en marzo de 1599, por instrucciones del oidor Juan del Barrio de Sepúlveda, dirigida por el padre Hernán González de Saá y con la participación del cacique Garcia Tulcanaza (gobernador de Tulcán, Malabas, Mayasquer y Barbacoas), se organiza una expedición para encontrar un camino más corto, menos penoso para salir al mar y también pacificar a los pueblos belicosos de Chicales y Barbacoas. [...] Partieron acompañados por cien indios [...] siguiendo la ruta que dejó el padre [Gaspar de] Torres en el Primer viaje, pasaron por las faldas del Chiles donde se admiraban de la gran cantidad de azufre: - que bueno como medicina y para hacer pólvora para la defensa ... decían; luego llegaron a Rumibais en cuyo lugar el cerro tiene la forma de una oreja...".

Ibarra (2004), en un artículo sobre el cacique García Tulcanaza, escrito para el periódico La Hora de Ecuador, al referirse a una travesía desde Quito hacia Esmeraldas (en el Ecuador), anota: "El 15 de enero de 1599 salió de Quito Hernán González con instrucción del señor Oidor, don Juan Barrio de Sepúlveda, con el fin de estudiar la manera de sacar un camino a Esmeraldas. Llegó a Tulcán, a treinta leguas de Quito; encontró a don García Tulcanaza, gobernador de Barbacoas Altas y Malabas, y al padre Fray Jerónimo de Aguilar, religioso de La Merced y cien indios más. Todos juntos partieron de Tulcán.". Más adelante añade: "El primer viaje caminaron tres leguas y durmieron al pie del volcán Chiles; el siguiente día, pasando páramos, ciénegas y mucho frío llegaron a Rumi-Huasi, que significa Casa de Piedra; y al tercer se encontraron con los primeros indios de Villa Viciosa, a dos leguas de San Felipe de Mayasquer, donde fueron bien recibidos y regalados.".

Con respecto a las transcripciones anteriores, el historiador ecuatoriano, director de la Unidad de Cultura de la ciudad del Ángel, Cantón Espejo, Provincia del Carchi, Luis Alberto Ibarra (Comunicación verbal, 2014), anota: "Para 1599 los pueblos indígenas de la región ya conocían al Chiles con su nombre y lo identificaban como un volcán (de hecho el volcán figuraba en los primeros títulos de propiedad de los cacicazgos)".

El hecho de que el Chiles fuera reconocido como volcán para la época (finales del siglo XVI), bien puede ser una evidencia de manifestaciones de su actividad en el periodo prehispánico, lo que igualmente queda reflejado en la etimología del nombre, del cual, en el volumen
1 de la revista del Instituto Histórico del Perú (1906) dice lo siguiente: "Otro [nombre] que tiene también componentes interpretables por la misma lengua es el volcán Chiles, como el anterior de la misma región; su etimología viene de "Chi" = resplandecer, "Li" = repetición y "s" = desinencia, es decir, que "alumbra con frecuencia".".

Ibarra, en comunicación verbal (2014), complementa que "esta expedición partió de Tulcán hacia Esmeraldas (en la costa pacifica ecuatoriana); que los expedicionarios pasaron por el sur del Chiles (pernoctando una noche al pie del volcán), donde encontraron azufre depositado, fuentes termales y lagunas verdes (en una de las cuales se bañaron); y que luego del hallazgo de azufre en esta zona, este elemento se empezó a extraer para la elaboración de pólvora.".

Cabe resaltar que para la época no se hace alusión a actividad fumarólica en el área de las lagunas verdes (flanco sur del Chiles), que como se verá más adelante, es la zona donde se reporta intensa actividad fumarólica en el siglo XIX.

Sobre el volcán Cerro Negro, se emplea en el documento transcrito por Tapia et al. (2011) el nombre indígena "Rumibais" y, al parecer es este grupo expedicionario el que da origen a la denominación "Cerro de la Oreja", con el que también es conocido el volcán Cerro Negro (o Cerro de Mayasquer, o Cerro Negro de Mayasquer).

La siguiente referencia histórica encontrada data de 1801, cuando Alejandro de Humboldt (1801) afirma lo siguiente: "El Chiles es una montaña nevada de gran volumen, pues en Tulcán y Mayasquer se cree verlo igualmente cerca, y ya que el páramo del Ángel también pertenece a su vertiente sur, se extiende hasta el valle del Chota. Algunos habitantes de Tulcán afirman que también el Chiles de vez en cuando humea; la mavor parte tiene la opinión contraria. Probablemente no es un volcán, a pesar de que su pórfido es totalmente parecido al de los volcanes de aqui." (Academia Colombiana de Ciencias Exactas Físicas y Naturales, 1982, pág. 239).

Su contemporáneo colombiano Francisco José de Caldas (1808) afirma: "En Tulcán (por 048') vuelven a renacer los dos ramos paralelos de los Andes en dirección Norte, y abrazan el valle de los Pastos, quizá el más elevado del universo. Tres cimas ardiendo (el Azufral, Cumbal y Pasto) y otra tranquila (Chiles). terminan su horizonte.". 


\section{2 - 1862. ACTIVIDAD FUMARÓLICA EN EL VOLCÁN CHILES Y POSIBLES ERUPCIONES MENORES}

Actividad fumarólica intensa del volcán Chiles, en 1852, es consignada en las descripciones de la Comisión Corográfica (Cuarta Expedición), cuyo objetivo era completar el mapa de la parte baja del río Magdalena y donde se exploró el valle del río Patía y se visitaron las provincias de Túquerres, Pasto, Popayán y el valle del río Cauca. Esta actividad fumarólica quedó plasmada en las pinturas hechas por Manuel María Paz (FIGURA 3).
El escritor y político colombiano Santiago Pérez M., quien en 1852 visitó la región del $\mathrm{CVChCN}$ como Secretario de la Comisión Corográfica, describió de manera poética (Pérez y Rodríguez, 1950): “... por el Sudoeste los volcanes activos de Chiles y Cumbal, ceñidos de una banda de nieve y tocando el cielo con sus largos plumajes de humo, que arquea y se lleva el viento en su dirección.".

Este mismo año, Agustín Codazzi visita la zona y deja plasmado en un mapa las características de los volcanes Chiles y Cumbal (Turchi, 2014; Barahona et al., 2002), indicando entre otros, la altura, la línea de nieve y la presencia de 7 bocas en el Chiles (FIGURA 4).

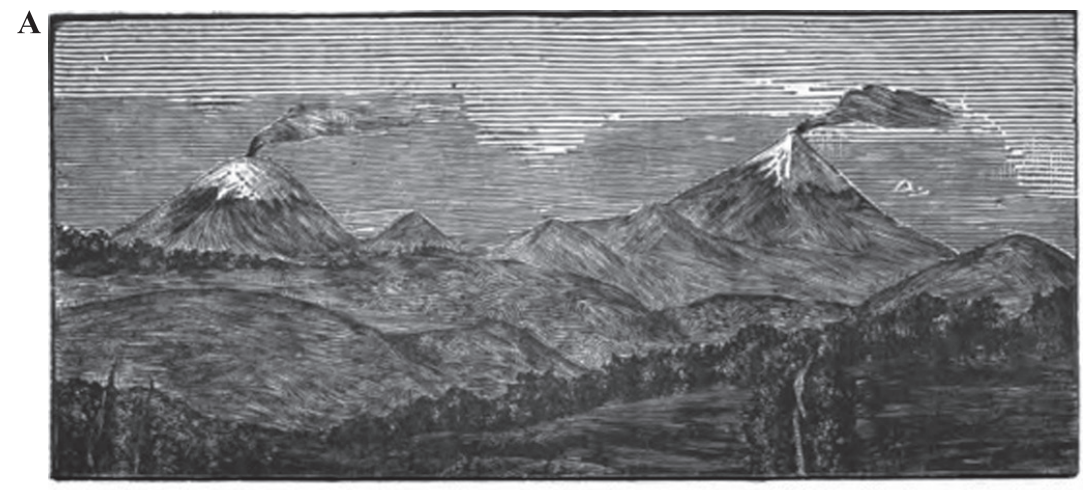

Figura i57-1.0s volcanes de Chiles y Cumbal sistos por el Oie ite. 1)el álbum de la Conisión Corngráfica. Inédito

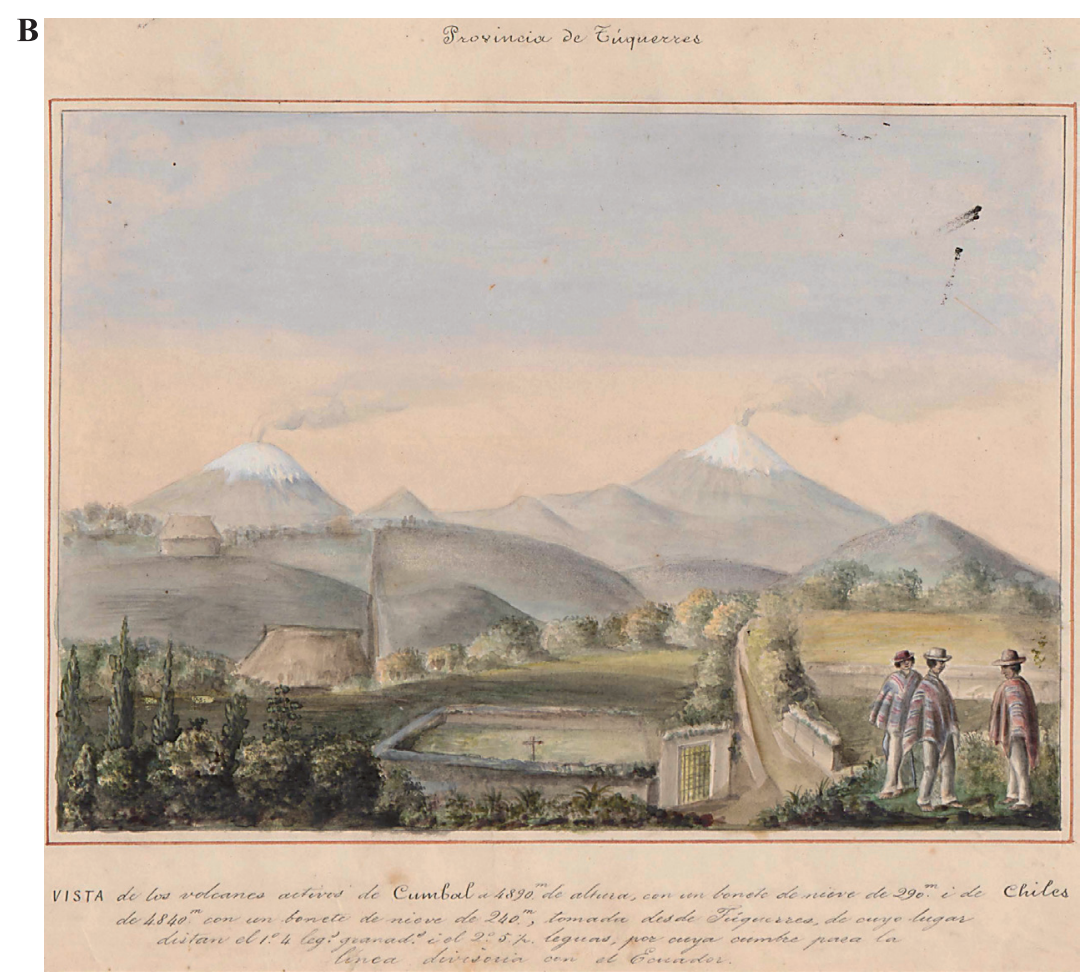

FIGURA 3. Actividad fumarólica en los volcanes Chiles y Cumbal, según dibujo de la Comisión Corográfica en 1853 . A. Tomado de Vergara y Velasco (1901). B. Pintura de Manuel María Paz, enero de 1853 (Biblioteca Nacional de Colombia, http:// www.bibliotecanacional.gov.co/recursos_user/bookreader/fc_corografica_5). 


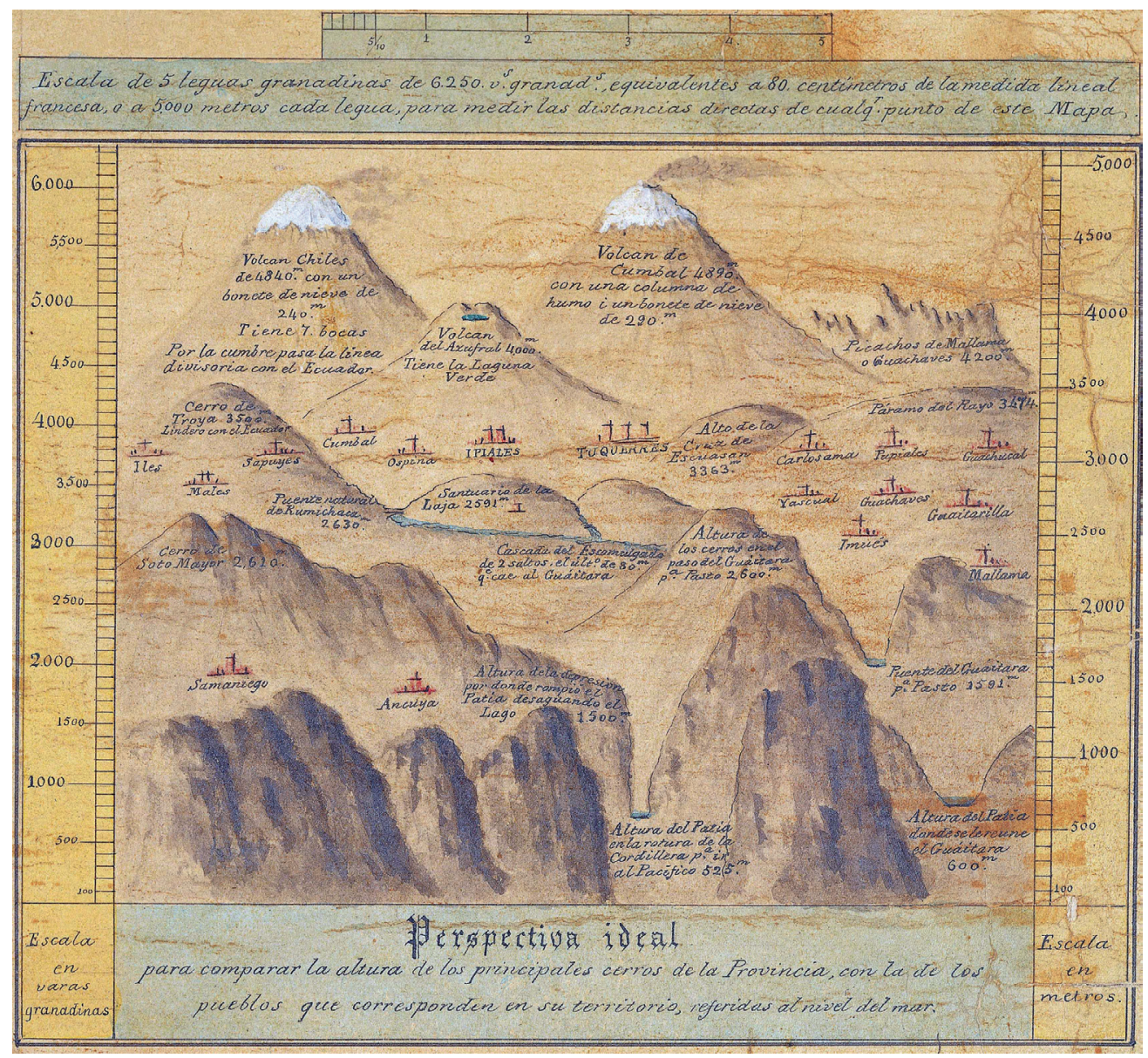

FIGURA 4. Mapa esquemático elaborado por Agustín Codazzi del área de los volcanes Chiles y Cumbal, tomado de Turchi (2014) (http://www.codazzi.mitreum.net/es/medida/cartografiacolombia.php).

En 1854, el naturalista alemán Karsten (1886), realizó observaciones de los volcanes Colombianos, entre ellos Chiles y Cerro Negro, de los cuales hace la siguiente descripción: "En el volcán de Chiles, con altura de 4.840 m., cubierto de nieve y cuyo cráter se encuentra en el flanco sur, por debajo del límite de las nieves perpetuas, potentes capas de conglomerados traquiticos recubren las partes del noroeste de estas rocas agrietadas y forman la región superior de una pared vertical de casi $1.000 \mathrm{~m}$ de altura. Probablemente esta capa, compuesta de bombas, escorias y cenizas volcánicas fue levantada con la lava traquítica subyacente".

Por su parte, Rodríguez Guerrero (1958) se refiere a este naturalista y su visita de la siguiente manera: "Karsten, geólogo eminente y botánico de primera fuerza, en una conferencia dictada en Viena en 1856, sobre la situación geonóstica de la Nueva Granada [...] pasa luego a hacer referencia, en otros capitulos, al volcán Chiles, en esta forma: "Lo mismo que en Guaca, el volcán Chiles está formado por bancos superpuestos de traquitas y de las grietas de las mismas salieron antes, como se puede deducir por los sedimentos de azufre, gases de azufre $y$ de hidrógeno, como también sucede actualmente en el segundo pico de Chiles, denominado pico de "La Oreja”... ". Lo transcrito por Rodríguez Guerrero se confirma con el dibujo elaborado por Karsten, en 1854, y publicado en su obra (Karsten, 1886). Este mismo dibujo (FIGURA 5) fue publicado recientemente por Aalto (2015).

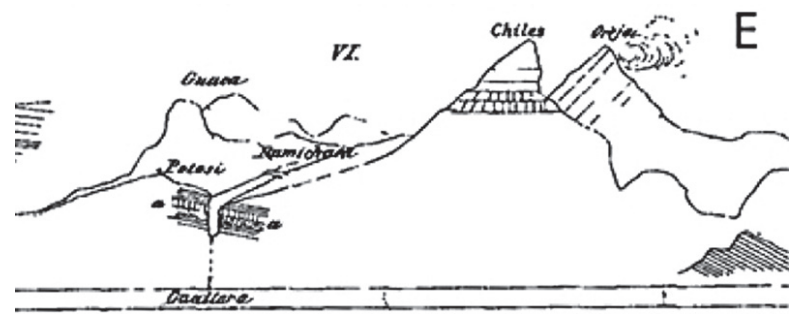

FIGURA 5. Segmento del perfil geológico sureste-noroeste trazado por Karsten en 1886, donde se observa a los volcanes Chiles y "Oreja" (volcán Cerro Negro), este último con signos de actividad fumarólica. Tomado de Aalto (2015). 
Con las anteriores descripciones y dibujos se confirma la actividad fumarólica tanto en el volcán Chiles como en el Cerro Negro para la época. En el Chiles, la columna de gases alcanzaba una altura importante sobre la cima del volcán, además de evidenciarse la presencia de un campo fumarólico activo o posible cráter en el sector de las Lagunas Verdes (FIGURA 6). En este sector (3.960 m.s.n.m.), actualmente, existen grietas y cavidades formadas, quizás por la antigua "actividad fumarólica", se perciben olores azufrados y presencia de dióxido de carbono, designándose como una zona de mofetas por su comportamiento a baja temperatura (Química Viviana Burbano, OVSPasto, comunicación escrita).

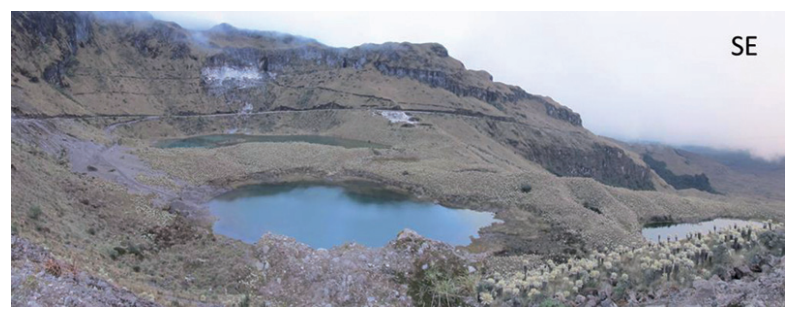

FIGURA 6. Vista parcial del sector de las Lagunas Verdes, en el flanco sur del volcán Chiles, del lado Ecuador, posible lugar donde se concentró una importante actividad fumarólica en épocas históricas y correspondiente a las "bocas" o posible "cráter" de que se hacía alusión en las descripciones en el siglo XIX.

La primera mención sobre actividad eruptiva en el volcán Chiles es referida por Manuel Villavicencio (1858), quien asegura: "CHILES: - Esta montaña volcánica se halla en la cordillera occidental en el lindero con la Nueva Granada: así es que la línea de demarcación pasa por las faldas de este i su compañero el volcán del Cumbal que se halla en terrenos granadinos. Es un cono truncado, algo regular; sus faldas son dilatadas, menos por el norte, donde pronto toca con las del Cumbal. Sus erupciones son de poca entidad $i$ no causan casi ningún estrago por la distancia en que se halla de los pequeños poblados. Su altura es de 5,734 varas sobre el mar; está situado a 30 millas N.N.E. de Ibarra.".

Es de tenerse en cuenta que se conoce de la existencia de las poblaciones de Chiles y Mayasquer (distantes de la cima volcánica unos $9 \mathrm{~km}$ al sureste y $15 \mathrm{~km}$ al noroeste, respectivamente) desde antes de 1686, como es señalado por el Presbítero José Benjamín Arteaga (1910). Adicionalmente, en el mapa de la región elaborado por Theodor Wolf (1898, en Stübel, 1906), basado en los datos tomados por Stübel y Reiss en 1869 y 1870, se cartografía la población de Chiles (con una altura de 3.143 m.s.n.m.), señalando que posee una capilla (FIGURA 7).
Pérez (1862), se refiere a los volcanes del sur de Colombia de la siguiente manera: "A lo lejos se presentan en toda su belleza acia al S-O. los dos volcanes nevados de Cumbal $i$ Chiles (distantes $2 i$ 2,5 miriámetros) que, bañados por los rayos del sol, hacen brillar sus cendales de nieve $\underline{i}$ dilatan en el espacio el humo de sus penachos devorado por los vientos del E; mientras que entre estos dos grandes conos de cúpulas blancas $i$ bases de color pajizo, sombreadas por los estribos salientes que reposan en la estensa llanura, se descubre mas allá todavía el pico del cerro Oreja, a cuyos piés pasa el camino que conduce al pueblo de indios de Mayasquer, situado en las bajas vertientes del Mira." (Pág. 225). Adicionalmente, en la página 234, este autor hace alusión sobre la actividad fumarólica hacia el flanco sur del volcán Chiles: "El volcán de Chiles tiene 15 bocas humeantes en la parte perteneciente al Ecuador, las cuales están en el flanco del cerro mucho más abajo de las nieves perpetuas.".

Posiblemente, Felipe Pérez retoma a Villavicencio (1858) en las publicaciones posteriores de la geografía de Colombia de 1876 y 1883, pues al referirse a los volcanes, hace mención a la actividad fumarólica del volcán Chiles, como en la publicación de 1862, agregando a su descripción: “... el de Chiles, que tiene más de 15 bocas humeantes (está en la línea divisoria con el Ecuador) i cuyas erupciones son de poca consideración..." (Pérez, 1876, pág. 58; 1883, pág. 356). Sin embargo, no hace ninguna otra mención o alguna referencia que aclare si hubo alguna actividad eruptiva entre 1862, cuando sólo se refiere a la actividad fumarólica, y 1876, donde agrega por primera vez la nota sobre las erupciones, información que ratifica años más tarde en su obra publicada sobre la "Geografía General del Nuevo Mundo" (Pérez, 1888): "[...] Chiles con 15 bocas, pero cuyas erupciones no son peligrosas $[\ldots]$ ".

En resumen, según los documentos históricos, para la época (décadas de los 50 y 60 del siglo XIX), el volcán Chiles presentó una intensa actividad fumarólica tanto en su cima como en su flanco sur, y posiblemente actividad eruptiva menor.

Como dato adicional, vale la pena anotar, que el 15 de agosto de 1868 ocurrió el Terremoto de Tulcán (Ramírez, 1975; CERESIS, 2015), sin encontrarse ninguna referencia a actividad de los volcanes Chiles y Cerro Negro. 


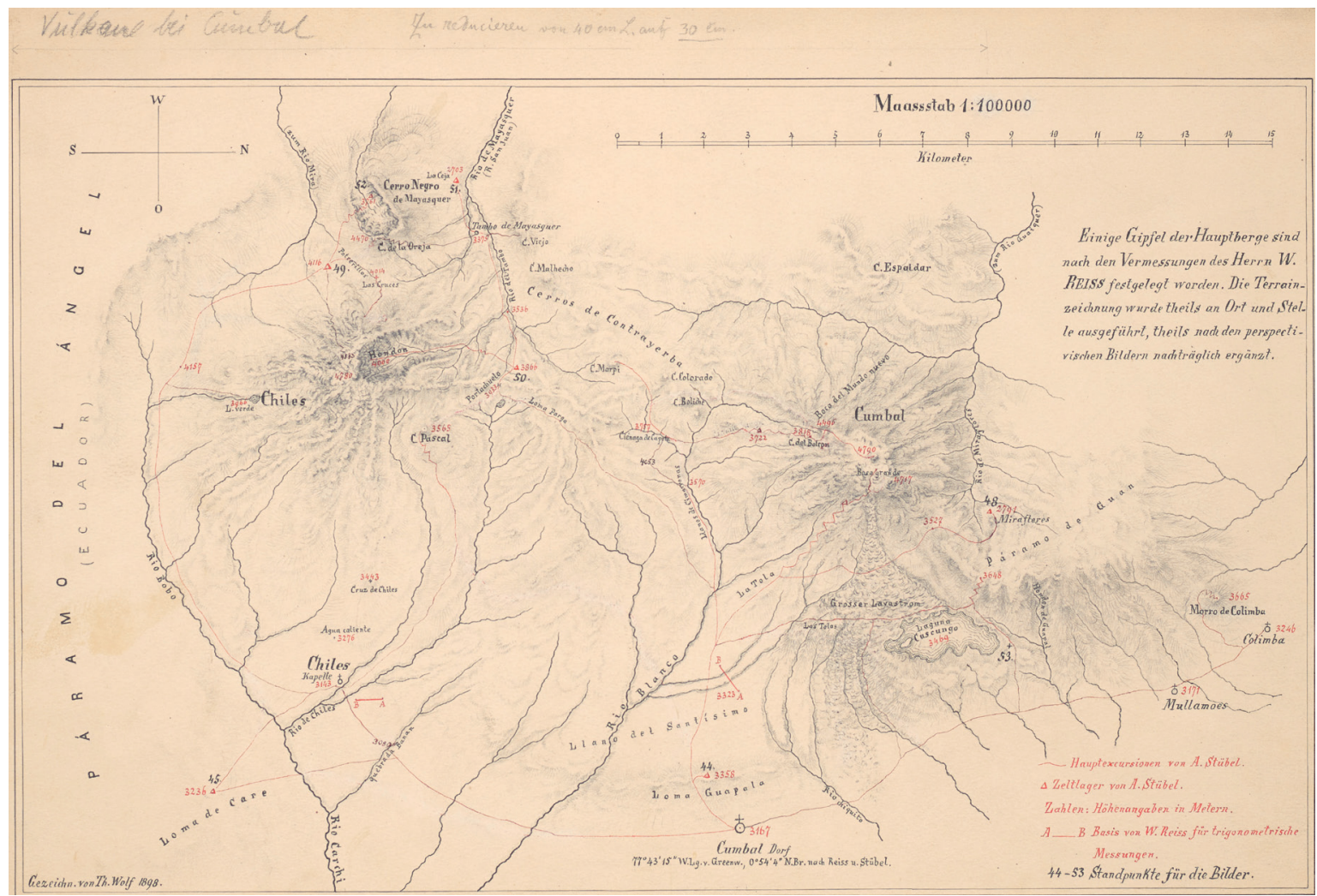

FIGURA 7. Mapa de la región de los volcanes Cumbal, Chiles y Cerro Negro elaborado por Theodor Wolf en 1898, sobre las observaciones y mediciones hechas por Stübel y Reiss en 1870. Tomado de Stübel (1906).

\section{ACTIVIDAD 1869 - 1910. ACTIVIDAD FUMARÓLICA EN EL VOLCÁN CERRO NEGRO.}

Hantke and Parodi (1966) describen al volcán Cerro Negro de Mayasquer (o Cerro de la Oreja), como un estrato volcán activo, truncado, con un cráter ovalado de 1.500 x 900 m, elongado en dirección SW-NE, que presenta una discontinuidad en su borde occidental con el fondo del cráter yaciendo a 3.652 m.s.n.m., el cual contendría un pequeño lago cratérico caliente, con $82^{\circ} \mathrm{C}$ de temperatura, de donde se escapaban gases de $\mathrm{H}_{2} \mathrm{~S}$ y $\mathrm{CO}_{2}$. Igualmente, hacia la orilla del lago y en la pared oriental del cráter indican la presencia de solfataras, con varios puntos de coloración amarilla por el azufre precipitado. Para 1869, referencian a Reiss como observador de actividad fumarólica en este volcán. Estos mismos autores se refieren al volcán Chiles como un volcán extinto, "mellizo" al Cerro Negro, abierto hacia el norte, cuya cima contiene una caldera de 2.000 $\mathrm{m}$ sin actividad volcánica.

Hönsch (1996) transcribe una carta de Stübel (escrita en Quito, el 15 de abril de 1870) en la que él hace el siguiente relato: “... realicé un nuevo viaje a los volcanes de Chiles y Cerro Negro que me tomaron catorce días. El volcán de Chiles tiene casi la misma altura del Cumbal, pero en su lado oriental, por causa de su figura en punta triangular, produce la impresión de ser sólo el resto de una montaña más bien de tamaño mediano. Esta impresión es producida por un profundo valle del cráter parecido al de la isla Palma (Canarias) y que lleva el nombre de valle del Hondón de Chiles. Después de pasar algunos días en los alrededores del Hondón, visité el cercano Cerro Negro y descendi al principio por su pendiente (externa) occidental desde la región de los páramos hasta tierra templada, donde se impone la montaña de manera muy hermosa. [...] Regresando por el mismo camino, ascendi la cumbre del Cerro Negro (4.460 metros) y de allí empezó el descenso por un profundo y estrecho cráter, del cual subía vapor en pequeñas cantidades. Las paredes de este volcán son tan empinadas que es imposible creer que se pueda descender en él: sin embargo nos fue posible (al doctor Reiss dos meses antes) alcanzar el suelo con toda nuestra carga...".

Como se puede apreciar de la corta descripción hecha en la carta sobre los volcanes, no hay por parte de Stübel, ninguna mención a actividad del Chiles, pero sí 
señala una pequeña actividad fumarólica para el Cerro Negro, aunque no indica la presencia del Lago cratérico al que hacen referencia Hantke and Parodi (1966). La FIGURA 8 muestra un ejemplo de los dibujos de Stübel, donde efectivamente no se aprecia ninguna actividad fumarólica.

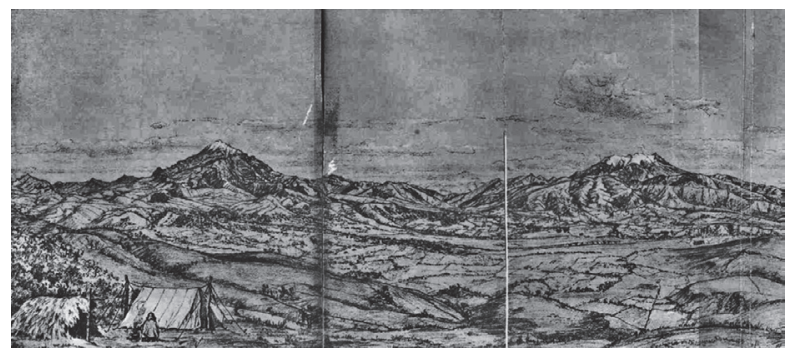

FIGURA 8. Dibujo de Stübel de los volcanes Chiles (izquierda) y Cumbal (derecha) en 1870, visto desde el sureste. Nótese la ausencia de actividad fumarólica para ésta época. Tomado de Stübel (1906).

Adicionalmente, Reiss y Stubel (1873) publican las alturas tomadas en la República de Colombia y hacen referencia, para el volcán Chiles, en el aparte "PUNTOS EN EL INTERIOR DE LA CALDERA, LLAMADA $E L$ "HONDON.", a la altura en que se encuentra dos fuentes termales denominadas: "Agua tibia, fuente del este a 3,790 m" y "Agua tibia, fuente del oeste a $3,759 \mathrm{~m}$ ", arrojando nuevos datos, para la época, sobre la actividad termal del volcán, mientras que para el volcán Cerro Negro, en el aparte "El Cerro negro de Mayasquer o Cerro de la Oreja. (Cerro volcánico.)", hacen referencia a una "Boca inferior, en la caldera", a 3.828 m. (pág. 192).

De las descripciones de Stübel se pensaría que a 1870 la actividad del Chiles habría cesado; sin embargo, la actividad de éste volcán para el año de 1877 , es consignada por Argüello (2007), en una investigación realizada sobre la actividad del volcán Cotopaxi en Ecuador. En la página 40, sin dar mayores detalles de la fuente original, se encuentra: "Los volcanes cuya actividad es incesante pero periódica en el Ecuador, son el Sangay, el Cotopaxi y el Chiles, éste al Norte de la República: otros apagados ó en aparente calma, son el Tungurahua, el Pichincha, el Quilota y la Calendaria, todos estos probablemente son cráteres de proyección, del mismo foco, que se alternan en la emisión á medida que varía el foco de combustión...".

Otro naturalista europeo, contemporáneo de Stübel y Reiss, Édouard André, comisionado por el gobierno francés, visitó la zona de los volcanes Cumbal, Chiles y Cerro Negro, entre finales de 1875 y principios de 1876; en su obra titulada "Viaje de M. Ed. André por la América Equinoxial" (André, 1883), haciendo la siguiente descripción:

"El cono del Chiles, que acabo de dibujar se levanta a cuatro mil ochocientos cuarenta metros sobre el nivel del mar. Una parte de su poderosa masa está situada en la Nueva Granada la otra pertenece al Ecuador. El cono del Chiles, de forma truncada, se presenta bastante regular: a su alrededor las laderas, entrecortadas por numerosos barrancos, son al principio alargadas, pero se acortan hacia el norte para entrelazarse con aquellas de Cumbal. Sobre los flancos que yo observo, las depresiones principales son aquellas por donde fluyen las primeras quebradas del rio Carchi. Este volcán está todavía activo. Muy por debajo de la zona de las nieves, se cuentan hasta 15 aperturas que dan paso a vapores sulfurosos. Sin embargo, las erupciones, hasta el presente, no han sido fatales a las zonas habitadas, situadas bastante alejadas del radio de peligro.".

Por su parte Wolf (1892), se refiere al volcán Chiles de la siguiente manera: "Conocemos esta vez al Norte, en la frontera de Colombia, donde encontramos el Cumbal y el Chiles (pág 99). Ambos volcanes se hallan actualmente en el estado de tranquilidad, pero no quisiera afirmar, que están apagados del todo y para siempre. Tienen calderas espaciosas. Aunque no sabemos nada de erupciones históricas (ila historia es en América tan corta!), las corrientes de lava bastante frescas a sus pies atestiguan, que su actividad llegó a una época muy moderna y post-cuaternaria...”.

Posiblemente este autor no tuvo conocimiento de la actividad de este volcán en los años anteriores, pues no hace referencia a la actividad fumarólica descrita en las décadas de los 50 y 60 del siglo XIX.

Vergara y Velasco (1901), describe al volcán Chiles de la siguiente manera: "El volcán de Chiles, que tiene quince bocas humeantes en la falda sur que pertenece al Ecuador, queda al $W$ del pueblo de Cumbal, del cual dista el cráter dos horas al través de rocas escarpadas. La cima la constituye una especie de cúpula rodeada de una cintura de hielo; al W. y un poco más abajo hay una hondonada á manera de cráter donde se oyen ruidos internos....".

Posteriormente, en 1907, el general Rafael Uribe Uribe, por entonces Ministro de relaciones exteriores de Colombia ante las Repúblicas del Sur, dijo en un discurso en Río de Janeiro, con motivo de la conmemoración del $97^{\circ}$ aniversario de la independencia de Colombia: "Vecinos a este país [refiriéndose al Ecuador] están los cuatro únicos volcanes en actividad que hay en 
Colombia: el Chiles, el Cumbal, el Galera y el Puracé.". (Sencial, 1908).

Como se extrae de los reportes correspondientes al periodo 1869 - 1907, las únicas descripciones que aportan datos diferentes, sobre los volcanes Chiles y Cerro Negro, son las de Reiss (Hantke and Parodi, 1966) y las de Stübel (1906 y en Hönsch, 1996); los demás autores se refieren posiblemente a la actividad que presentó el volcán Chiles antes de los años 60 del siglo XIX, ya que dichas descripciones son similares a las que se tienen para el periodo de 1852 - 1862, aunque ellos no hacen ninguna referencia a documentos previos.

Reafirmando la idea del cese de la actividad del volcán Chiles después de 1870 y el aumento en la actividad del volcán Cerro Negro, el Presbítero José Benjamín Arteaga (1910), hace alusión a estos volcanes de la siguiente manera: "El nevado de Chiles mide 4.840 metros de altura y como no tiene cráter, nos parece que impropiamente se lo llama volcán; á no ser que se considerara como cráter el volcán de la "Oreja", llamado así porque su enorme abertura semeja el pabellón de una oreja. Es una continuación hacia el Occidente, si bien entre ambas enhiestas cimas se interpone una meseta de 51 cuadras toda ella cruzada de caminos ó vericuetos, para paso de los contrabandistas o para tránsito de ganado que va á los grandes páramos de Potrerillos. De este volcán no hacen mención los geógrafos, no obstante ser activísimo, pues vomita fuego y humo continuamente a una altura de 4.292 metros y termina sobre el Cascarillo.".

Teniendo en cuenta que el Presbítero Arteaga fue un reconocido historiador de la época (Chamorro, 1987; Instituto de Cultura y Turismo de Pasto, 2014) y a la rigurosidad en su investigación histórica y en las descripciones geográficas y demográficas de la zona en la obra citada, consideramos que a pesar de ser el único autor que hace mención directa a la actividad eruptiva del volcán Cerro Negro, este documento es una fuente fiable de información. La actividad reportada por el autor, podría igualmente validarse por las descripciones de Reiss y Stübel, sobre las manifestaciones termales y fumarólicas y la presencia de un cráter al interior del anfiteatro hacia finales del siglo XIX, del cual en la actualidad no hay vestigios (lo que podría indicar algún tipo de actividad que lo haya destruido).

\section{REPORTE DE ACTIVIDAD 1923- 1936}

En Espinosa (2011) se señala actividad general en el volcán Chiles : "En 1923, año en que Karl Sapper hizo su recorrido por Colombia, el Chiles daba algunas señas de actividad pues refiriendose a Sapper, Rodríguez Guerrero (1961) anota: “...del cumbal anota que mantiene una columna de humo en la cima, la cual se halla a 4.790 metros de altura, y lo propio del Chiles cuya altura es de 4.840 metros...".".

Desde finales de 1923 y comienzos de 1924, en la zona del CVChCN, se registró una importante sismicidad; en algunos casos, los sismos fueron asociados por la población a actividad eruptiva del volcán Chiles. Al respecto, en la página web del IGEPN (http://www. igepn.edu.ec/index.php/un-dia-como-hoy) se encuentra: "14/12/1923. Terremoto con grave afectación en la provincia del Carchi. Uno de los terremotos con mayores consecuencias en la provincia del Carchi, hasta esa fecha. Se cayeron muchas casas, en especial en los pueblos y sectores rurales y campesinos. Deslizamientos en montes, laderas y taludes, dejan caminos inhabilitados. Desperfectos en muchos edificios públicos, escuelas y sobre todo daños serios en viviendas. Tulcán, Ipiales, Cumbal, Carlosama, Aldana, Chiles, Túquerres y otros caseríos aledaños fueron los lugares más quebrantados. 20.000 personas quedaron sin vivienda. Grandes y numerosas grietas $y$ deslizamientos en el área macrosísmica. Quedaron borrados los caminos. Testigos presenciales afirmaron haber visto actividad eruptiva en el volcán Chiles, hacia el lado occidental. Cerca de Tulcán aumenta el caudal de una fuente termal. Murieron unas 300 personas, (con exageración se habló de 3.000 víctimas). Algunas notas de prensa afirmaron que paralelamente al terremoto habia erupcionado el volcán Chiles. Investigación realizada por José Egred A.".

De Espinosa (2011) se transcribe la información consignada, para 1923, por dicho autor: "VOLCÁN DE CHILES... El Diario del Sur informa desde Pasto el 15 de diciembre de 1923: El Chiles busca cráter. Enormes grietas, llamaradas en el Chiles. El hambre y la desnudez hacen presa...".

"Ipiales, 16 de diciembre de 1923. DIARO SUR PASTO. Desde 12 noche hasta este momento, seis (6) temblores sintiéronse aqui y en Tulcán, que hannos obligado a amanecer al intemperie. El de las tres fue más fuerte y largo causando nuevas gravísimas averías edificios. Témese estos últimos movimientos hayan concluido con ruinas Cumbal. Comunicación interrumpida. Oyense horribles bramidos, créese nevado Chiles busca apertura cráter. [...] Personas visitaron ese teatro desolación, ruinas, informan que en faldas nevado hanse abierto enormes grietas y terrenos toda esa región hállanse como arados. Quebradas "Panan", "Cumbal," secáronse completamente. 
Jueves noche, víspera de terremoto, vecinos Chiles, Cumbal dicen vieron llamaradas de fuego cima Chiles. Sobrevivientes Chiles, Cumbal, Carlosama lloran hambre, desnudez...".

Espinosa (2011) continúa: "El día siguiente el mismo periódico dice: "Ipiales 16. Gobernador-Pasto. Volcán chiles no ha hecho erupción. Tiénese conocimiento hanse abierto grandes grietas en Haciendas Chautalá $y$ trayecto entre Cumbal y Chiles... CLIMACO BURBANO, Prefecto.".

"Ipiales, 17 de diciembre de 1923. Juliob. - Pasto. Insignificantes daños casas. No crea mentiras. Aquí generalmente todos bien. Ayer fui a Tulcán, las casas están todas seriamente averiadas, créolo destruido. Parece volcán chiles explosionó para Mayasquer, conceptúo pasó todo peligro; anoche, hoy nada sentimos. SANTACRUZ'.

"El mismo día, en Cali el Correo del Cauca informa: "El terremoto del Sur. Pasto, 15. - Correo. - Ayer a las cinco y media de la mañana se sintió fuerte movimiento sísmico. Las noticias provenientes de Ipiales son alarmantísimas. La causa del terremoto supónese sea el Cerro Chiles... Corresponsal".

"Pasto, 16, "Correo. -... El jefe de la policía de fronteras solicita de la gobernación el apoyo fiscal, a fin de practicar una excursión y transmontar el cerro de Chiles para informarse si según se cree está haciendo explosión en dirección a Mayasquer. Corresponsal".

"Y el 19 de diciembre: "Completos detalles de los terremotos del Sur. Pasto, 18 - inspector general Domínguez - Cali. Permítome transmitir, por vía de información, los datos verídicos de los siniestros del sur. [...] La Población de Chiles fue la primeramente destruida, se secaron las quebradas que nacian del páramo del mismo nombre; se cree que sea la causa este cerro de la inmensa catástrofe, pues presenta enormes grietas... Corresponsal" ".

Con respecto al sismo del 14 de diciembre de 1923 y sus efectos, Sarabia y Cifuentes (2007) presentan la siguiente información: "El viernes 14 de diciembre de 1923, aproximadamente a las 5 y 30 de la mañana, hora local, se registró un sismo al sur del departamento de Nariño, cerca de la frontera con Ecuador. El epicentro fue localizado en $1^{\circ} \mathrm{N}-77^{\circ} \mathrm{W}$ y la magnitud estimada (Ms) fue de 7 en la escala de Richter. El radio de acción del sismo fue bastante pequeño, ya que los mayores daños se concentraron en un área aproximada de $130 \mathrm{~km}^{2}$. Las poblaciones más afectadas y que prácticamente quedaron destruidas, fueron: Cumbal, Cuaspud (Carlosama), Aldana, Panán y Chiles. [...] También se registraron bastantes réplicas desde el día del sismo hasta el 21 de diciembre, de las que sobresalen 3 ocurridas en la madrugada del 16 de diciembre, las cuales aumentaron en gran medida los daños que ya había...".

En este informe también se transcriben del diario El Tiempo, del 16 de diciembre de 1923, algunas descripciones donde también se hace alusión al volcán Chiles:

"LOS GRANDES TERREMOTOS DE LA FRONTERA SUR DETALLES COMPLETOS DE LA CATÁSTROFE [...] Extra. Oficial, 10 y 40 p.m. Ipiales, 14 de diciembre de 1923. Administrador General. Telégrafos. Bogotá. [...] Acaban comunicar de Quito: Sismógrafo no hase registrado en observatorio. Temblor sintiéronlo lento. Obsérvase aqui por acontecimientos terribles, obedece a volcán Chiles. Servidor, Martínez.G., Telegrafista...".

"Ipiales, diciembre 15. TIEMPO - Bogotá. [...] La población de Chiles, situada en la falda de la montaña donde está el volcán del mismo nombre, fue totalmente destruida, pero no se tienen detalles, porque nadie se atreve a acercarse, debido a la actividad del volcán [...] CORRESPONSAL".

"El Diario del Sur diciembre 20 de 1923. Auxilios. Pasto, 16. General Pedro Nel Ospina, Nuevo Tiempo - Bogotá. Ante calamidad pública, repentina, de municipios Cumbal, Aldana, Carlosama, Guachucal por terremoto Volcán Chiles que ha aniquilado poblaciones, haciendas, etc., atrévome suplicar un auxilio, nombre huérfanos, viudas, heridos, que sin pan, vestidos ni hogar, vagan ahora campos desolados. Corregimiento Chiles desapareció. En Cumbal vélanse ciento veinte cadáveres...".

Igualmente, la sismicidad en enero de 1924, se atribuye a la actividad volcánica del Chiles. La Revista Credencial Historia (2006): "Colombia y el Mundo 1924. Enero 10. Violentos temblores sacuden el Departamento de Nariño, movidos por erupciones del volcán Chiles. Quedan destruidas las poblaciones de Carlosama, Tundama y Aldana...".

Las menciones hechas sobre la actividad eruptiva del volcán Chiles en los reportes citados anteriormente, aunque reiterativas, son muy vagas, lo que puede ser debido, como lo señala Espinosa (2011), a: “...como se ve en los textos anteriores, hay una gran confusión y varias contradicciones sobre el posible comportamiento 
del volcán en relación con los terremotos que destruyeron el sur de Nariño el 14 de diciembre de 1923 y los días siguientes. Más por tradición que sobre la base de observaciones, en ese caso como en muchos otros se atribuye el sismo al volcán más cercano.”.

No obstante, se debe tener en cuenta que pese a que en 1868 la zona tambíen fue fuertemente afectada por el llamado “sísmo de Tulcán”, el 15 de agosto de ese año (Ramírez, 1975; CERESIS, 2015), hasta el momento no se ha encontrado ningún documento donde se haya atribuido este sismo a la actividad eruptiva de estos u otros volcanes cercanos. Aunque confusas y poco detalladas, para 1923 se encuentran algunas descripciones que evidenciarían actividad eruptiva (llamaradas, bramidos) y hasta el temor hacia esta actividad, como se puede apreciar de los siguientes extractos, de las fuentes referidas anteriormente, los cuales hacen alusión directamente al volcán Chiles:

- “...Jueves noche, víspera de terremoto, vecinos Chiles, Cumbal dicen vieron llamaradas de fuego cima Chiles".

- "Enormes grietas, llamaradas en el Chiles..."

- Oyense horribles bramidos, créese nevado Chiles busca apertura cráter.".

- "La población de Chiles, situada en la falda de la montaña donde está el volcán del mismo nombre, fue totalmente destruida, pero no se tienen detalles, porque nadie se atreve a acercarse, debido a la actividad del volcán..."

La principal confusión con respecto a la actividad radica en que, en algunas citas, se menciona que ésta ocurrió hacia el lado occidental del Chiles:

- "Testigos presenciales afirmaron haber visto actividad eruptiva en el volcán Chiles, hacia el lado occidental.".

- "Parece volcán chiles explosionó para Mayasquer...".

- “...si según se cree está haciendo explosión en dirección a Mayasquer.".

Es poco probable que el volcán Chiles haya hecho erupción hacia el lado occidental, ya que presenta un anfiteatro orientado en dirección norte y no se encuentran evidencias de un cráter o un foco eruptivo hacia su flanco occidental (el cual colinda con las faldas del volcán Cerro Negro). Sin embargo, vale la pena recordar que algunas veces se identifica indistintamente un solo volcán refiriéndose a Chiles y Cerro Negro. En este caso, es posible que la actividad eruptiva hubiera ocurrido en Cerro Negro (refiriéndose a él como el Chiles), el cual al parecer era, de estos dos, el volcán reconocido como activo en años inmediatamente anteriores a 1923. Esto aunado a la escasa población con visual hacia el volcán, una posible actividad eruptiva menor y la ocurrencia misma de los sismos (que causaron confusión debido a la destrucción y pérdidas de vidas humanas en el área), podría explicar la poca información y documentación de la actividad eruptiva.

A pesar de las múltiples menciones a la actividad eruptiva, en 1923, del volcán Chiles, según FINCIC (en Cortés y Calvache, 1997): “...en entrevistas con gente mayor en la zona no recordaban haber visto el volcán en erupción"; sin embargo, tampoco hacen alusión al terremoto, razón por la cual sería importante tratar de indagar más sobre los dos fenómenos con los descendientes de los pobladores de la zona.

Araíz de los sismos sentidos en la región, debido a la actual reactivación del Complejo volcánico, principalmente el registrado el 20 de octubre del 2014, la Agencia Pública de Noticias del Ecuador y Suramérica (Andes), en un reportaje reciente sobre estos sismos (http://www.andes. info.ec/en/node/36006), algunos de los habitantes traen a la memoria hechos relacionados con la sismicidad de 1923: "Tufiño, Ecuador, 25 oct [2014](Andes).- Los habitantes de esta comunidad turística y agropecuaria, ubicada en la zona de influencia de los volcanes Chiles y Cerro Negro, en la frontera entre Ecuador y Colombia, se sienten nerviosos desde el pasado lunes cuando un sismo de 5,9 grados sacudió sus viviendas. En el lugar reina la incertidumbre ante la creciente actividad de los volcanes que tienen a la provincia de Carchi en alerta naranja, un nivel menos que la alerta máxima o roja. "Esa tarde estaba arando cuando vino un bramido bien fuerte. Este caballo se corrió del susto”, relata Pedro Paspuel, habitante de Tufiño. Los últimos sismos hicieron que Victor Chiles recuerde cuando su padre le relató el terremoto de 1923, que abrió las grietas por donde se filtra el agua de las piscinas termales que ahora son atractivo para los turistas. Los habitantes de esa zona de Ecuador y las autoridades siguen atentos cualquier cambio en el comportamiento de los volcanes.".

Para el año de 1936, Hantke and Parodi (1966) hacen alusión a una erupción el 17 de julio de ese año, como evento de cráter central, con cenizas y "bramidos" y se cuestionan si es del volcán Cerro Negro o del Reventador (?). Espinosa (2011) hace alusión igualmente a esta actividad pero no hace transcripción de textos por falta de datos que la sustenten. También vale la pena tener en cuenta que en el transcurso el año 1936 el volcán Galeras registró una importante actividad eruptiva (Ramírez, 1975). 
Adicional a esta información, el diario "Milwaukee Journal" de Estados Unidos, en su edición de julio 19 de 1936, en la página 3 (FIGURA 9), consigna una noticia respecto a eventos eruptivos de una "montaña volcánica" cerca al volcán Cerro Negro, asociados a los sismos registrados en julio de 1936. Sin embargo, los datos aportados son ambiguos y no es posible, a partir de la noticia, interpretar cual fue el volcán que arrojó cenizas en la región. Los sismos referidos en esta noticia ocurrieron entre el 14 y el 18 de julio de 1936 y causaron importantes daños materiales y pérdida de vidas humanas (Cerón-Solarte, 2016).

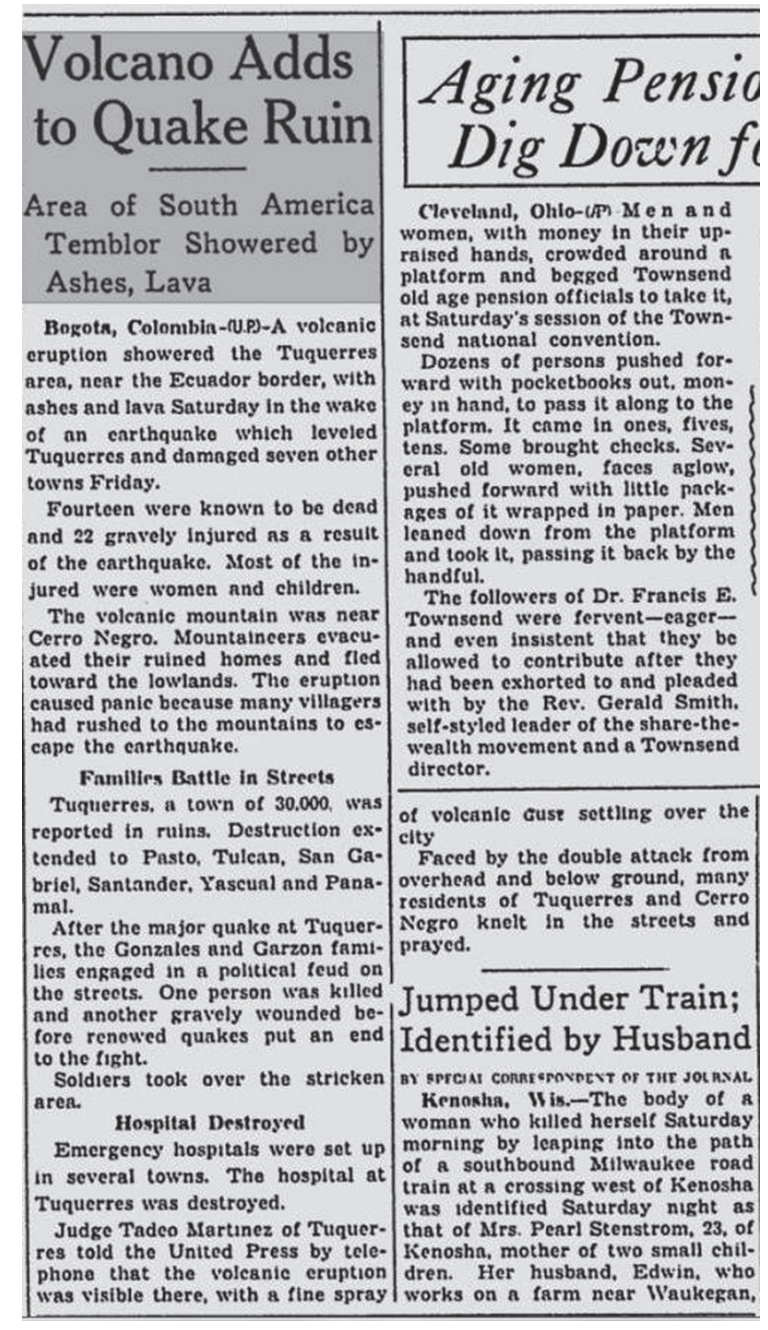

FIGURA 9. Noticia respecto a posibles eventos eruptivos en el volcán Cerro Negro, asociados al sismo del 17 de julio de 1936 (The Milwaukee Journal, Sunday july 19 1936, pag. 3).

Ya en la década de los cuarenta, el geólogo del Servicio Geológico Nacional, José Royo y Gómez hace las siguientes observaciones sobre los volcanes Chiles y Cerro Negro: "En el volcán Chiles no he visto fumarolas, pero según me informaron alli, existen aún algunas en un cono occidental pequeño llamado El Oreja, situado en la misma frontera con el Ecuador." (Ministerio de Minas y Petróleos de Colombia, 1942).

\section{DISCUSIÓN Y CONCLUSIONES}

Como aporte al conocimiento del CVChCN, este trabajo presenta una recopilación y análisis de documentos históricos, que hacen referencia a su posible actividad eruptiva.

En los siglos pasados, algunos naturalistas hacen mención, aunque a veces de manera contradictoria, sobre la actividad del $\mathrm{CVChCN}$ en tiempos históricos. Esto igualmente sucede con los reportes sobre la actividad en épocas más recientes, por autores posteriores y la información consignada en periódicos nacionales e internacionales. El hecho de que algunos autores identificaran a los volcanes Chiles y Cerro Negro como uno solo, también hace confusas las interpretaciones. La escasa población hacia ese sector y especialmente en el siglo XIX, explicaría que las descripciones de la actividad sean imprecisas.

Los datos y descripciones de los documentos recopilados en este trabajo son interpretados como indicio de que en épocas prehispánicas e históricas el volcán Chiles presentó actividad eruptiva. En el siglo XIX la presencia de fumarolas estuvo posiblemente asociada a actividad eruptiva entre 1850 y 1860 , la cual es señalada algunas veces hacia el sector de las Lagunas Verdes en el flanco sur del volcán (en el Ecuador). Según las condiciones actuales del área, éstas podrían haber sido erupciones menores de tipo freático a freatomagmático. Es necesario llevar a cabo trabajos detallados de campo en ésta zona que permitan confirmar o descartar ésta hipótesis.

Igualmente, las descripciones apuntan a que mientras hay un cese en la actividad del volcán Chiles hacia finales del siglo XIX, ésta aumenta en Cerro Negro, e inclusive se hace alusión a su actividad eruptiva frecuente a comienzos del siglo XX (alrededor de 1910) y actividad fumarólica aún en los años cuarenta, pero no se han encontrado documentos que permita conocer el tipo de actividad ocurrida.

En el siglo XX, la intensidad y efectos de los episodios sísmicos en 1923-1924 y 1936 en la región "opacaron" las alusiones directas a actividad eruptiva (bramidos, llamaradas, cenizas, etc.), haciendo la información confusa y no suficiente para confirmar esta actividad. Sin embargo, una investigación histórica más profunda podría arrojar datos más claros al respecto. 
Por estar fuera del alcance del presente trabajo y con el fin de conocer y confirmar información sobre actividad histórica de estos volcanes, se sugiere seguir las recomendaciones plasmadas en Cortés y Calvache (1997) de hacer una revisión en las cabeceras municipales de Guachucal y Cumbal, en las inspecciones de policía, los archivos parroquiales y en el archivo de las comunidades indígenas de la zona. Estas autoras anotan: “... según el inventario del departamento existe documentación de las alcaldias desde 1670 a 1985 y en la parroquia San Pedro de Cumbal desde 1798 hasta 1895"; e igualmente sugieren: "... Hacer investigaciones del mismo tipo en ciudades como Tulcán e Ibarra (Ecuador)".

Se sugiere realizar encuestas con los descendientes de los pobladores de Mayasquer y localidades aledañas que puedan arrojar más datos sobre los fenómenos naturales ocurridos en el siglo pasado.

Se recomienda hacer una traducción completa de los textos de Stübel (1906), conseguir y traducir los textos de Wilhem Reiss, quien estuvo en la zona dos meses antes que Stübel. Igualmente, sería conveniente hacer una revisión más exhaustiva de la obra de Arteaga, que según Chamorro (1987) se encuentra en su mayoría inédita.

De acuerdo a la actividad actual del complejo volcánico y los relatos históricos se sugiere tomar en cuenta para la amenaza del volcán Chiles un escenario que tenga como foco de actividad el sector de las Lagunas Verdes.

\section{AGRADECIMIENTOS}

Al personal del SGC - Observatorio Vulcanológico y Sismológico de Pasto (OVSPasto) por su colaboración con información sobre la actividad más reciente de los volcanes Chiles y Cerro Negro. A Mónica Arcila y Ana Milena Sarabia, de la Dirección de Geoamenazas del SGC, por aportar información sobre sismicidad histórica en la zona. A Bernardo Oscar Beate, del Instituto Geofísico de la Escuela Politécnica Nacional de Quito (Ecuador), por el apoyo en la traducción de algunos textos en alemán de Stübel y Reiss. A Luis Alberto Ibarra Revelo, Director de la Unidad de Cultura de la ciudad del Ángel, Cantón Espejo, Provincia del Carchi (Ecuador), por compartir con nosotros su conocimiento respecto a la historia de la región de los volcanes Chiles y Cerro Negro. A Lizeth Vanessa Torrres Mori por su apoyo en la búsqueda de información en la Internet. A Carlos José Muñoz, del OVSPasto, por su apoyo en temas cartográficos. Y a Marta Lucía Calvache, Directora de Geoamenazas del SGC, por su apoyo al permitir el desarrollo de este trabajo. Finalmente, agradecemos a los revisores de este artículo por sus comentarios y aportes: Dr. Armando Espinosa Baquero, Dr Benjamín Bernard del IGEPN y evaluador anónimo.

\section{REFERENCIAS}

Aalto, K.R. 2015. Hermann Karsten, pioneer of geologic mapping in northwestern South America. History of Geo and Space Sciences, 6: 57-63.

Academia Colombiana de Ciencias Exactas Físicas y Naturales. 1982. Alexander von Humboldt en Colombia. Extractos de sus diarios. Publicismo y Ediciones. Bogotá, 247p.

Agencia Pública de Noticias del Ecuador y Suramérica "Andes". 2014. Fotoreportaje: Cómo relatan el temblor los habitantes de las faldas del volcán Chiles, entre Ecuador y Colombia. 25 de octubre de 2014. Consultado el 15 de noviembre de 2014. http://www.andes.info.ec/ en/node $/ 36006$

André, E. 1883. L'Amerique Equinoxiale. Le Tour Du Monde Semanaire, 1170: 337-416.

Argüello, C. 2007. Introducción teórica, base de datos sobre la erupción del Volcán Cotopaxi de 1877. Universidad de las Fuerzas Armadas ESPE. Quito, 144p. Consultado el 4 de diciembre de 2014. http:// repositorio.espe.edu.ec/bitstream/21000/2922/1/LESPE-000601.pdf.

Arteaga, J.B. 1910. Apuntamientos sobre Mayasquer y Cumbal. Imprenta departamental. Pasto, 88p.

Banco de la República. 2014. Láminas Comisión Corográfica - Manuel María Paz. Consultado el 30 de noviembre de 2014. http://www.bibliotecanacional.gov. co/recursos_user/bookreader/fc_corografica_5/index. html.

Biblioteca Nacional de Colombia. 2014. Láminas Comisión Corográfica - Manuel María Paz. Consultado el 30 de noviembre de 2014. http://www. bibliotecanacional.gov.co/recursos_user/bookreader/ fc_corografica_5/index.html.

Barahona, G., Domínguez, C., Gómez, A., y Figueroa, A. 2002. Geografía Física y Política de la Confederación Granadina, Estado del Cauca, Provincias del Chocó, Buenaventura, Cauca y Popayán, Provincias de Pasto, Túquerres y Barbacoas. Obra Dirgida por el General Agustín Codazzi. Editorial Universidad Del Cauca. Popayán, 458p. 
Burbano, R.V., y Valencia, F. 2014. Informe Mensual de Geoquímica del Volcán Galeras, Volcán Chiles y Cerro Negro, Octubre de 2014. Observatorio Vulcanológico y Sismológico de Pasto, Servicio Geológico Colombiano, Pasto, 34p.

Caldas, F.J. 1808. Estado de la Geografía del Virreinato de Santafé de Bogotá, con relación a la economía y el comercio. Semanario del Nuevo Reino de Granada, Vol. 1. Consultado el 1 de diciembre de 2014. http://www. bdigital.unal.edu.co/95/1/estado_de_la_geografia.pdf

Centro Regional de Sismología para América del Sur (CERESIS). 2015. Catálogo de Intensidades para Colombia. Consultado el 15 de diciembre de 2015. http://www.ceresis.org/catalogos/intensidades/inten colombia.DAT

Cerón-Solarte, B. 2016. Actividad sísmica en Pasto y las provincias del sur, 1834 - 1953. Manual de Historia de Pasto, Tomo XVII. Academia Nariñense de Historia. Graficolor. Pasto, pp. 238 - 277.

Cortés, G.P., y Calvache, M.L. 1997. Informe sobre la evaluación de la amenaza volcánica del Chiles y Cerro Negro. Mapas de Amenaza. Primera versión. Observatorio Vulcanológico y Sismológico de Pasto, INGEOMINAS. 43p.

Chamorro, J. 1987. Aproximación a la historia de la literatura Nariñense. Correo de Nariño. Pasto, 176p.

Delgado, J.M. 2004. Crónica de los Pastos. Abya-Yala. Quito, 168p.

Espinosa, A. 2001. Erupciones históricas de los volcanes colombianos (1500 - 1995). Revista de la Academia Colombiana de Ciencias Exactas, Físicas y Naturales. Colección Jorge Álvarez Lleras, 16: 291p.

Espinosa, A. 2011. Erupciones históricas de los volcanes colombianos $(1500-2000)$. Enciclopedia de Desastres Naturales históricos de Colombia, Volumen 6, Segunda edición. Academia Colombiana de Ciencias Exactas, Físicas y Naturales. Universidad del Quindio. Armenia, 453p.

Hantke, G., and Parodi, A. 1966. Catalogue of the active volcanoes and solfatara fields of Colombia, Ecuador and Peru. IAVCEI. Roma, 73 p.

Hönsch, I. 1996. Los viajes de investigación de Alphons Stübel por sudamérica $(1868$ - 1877) a través de su correspondencia. En: Tras las huellas: dos viajeros alemanes en tierras latinoamericanas. Biblioteca Luis Ángel Arango. Consultado el 10 de noviembre de 2014. http://www.banrepcultural.org/blaavirtual/historia/hue/ hue $3 . h t m$

Humboldt, A. 1801. Vida de Humboldt. Extractos de sus diarios. Viaje de Pasto a Quito. Consultado el 30 de octubre de 2014. http://www.banrepcultural.org/ blaavirtual/exhibiciones/humboldt/diario/41.htm

Ibarra, L. 2004. García Tulcanaza, un luchador infatigable. Consultado el 5 de noviembre de 2014. http://www. lahora.com.ec/index.php/noticias/show/1000239255/-1/ home/goRegional/El\%20Oro\#.VI445iuUeSp

Ibarra, V. 2003. Leyenda Pasto: Embilput y Embilquer. Consultado el 15 de enero de 2016. http://ahora.com. ec/index.php/noticias/show/1000206634/-1/Leyenda Pasto\%3A_Embilput_y_Embilquer.html\#.Vs3Fw_nhB1 $\bar{N}$

Ibarra, R., Antonio, L., y Romero, R. 2011. La visión histórica de la cultura Pasto prehispánica y su incidencia en la formación de los alumnos de primer curso de bachillerato del área de ciencias sociales del Colegio Nacional Libertad. Universidad Tecnológica Equinoccial. Ibarra, 265p.

Instituto de Cultura y Turismo de Pasto. 2014. Otros historiadores representativos del departamento de Nariño. Consultado el 7 de noviembre de 2014. http:// www.culturapasto.gov.co/index.php/nuestra-cultura/45historiadores-representativos/208-otros-historiadoresrepresentativos-del-departamento-de-narino/

Instituto Geofísico de la Escuela Politécnica Nacional de Quito - Ecuador (IGEPN). 2014. Un día como hoy. $14 / 12 / 1923$. Terremoto con grave afectación en la provincia del Carchi. Consultado el 20 de noviembre de 2014. http://www.igepn.edu.ec/index.php/un-diacomo-hoy

Instituto Histórico del Perú. 1906. Revista histórica: Órgano del Instituto Histórico del Perú. Volumen 1. Lima, 476p.

Karsten, H. 1886. Géologie de L'Ancienne Colombie Bolivarienne. Vénézuela, Nouvelle-Grenade et Ecuador. R. Firedländer and Son. Berlin, 95p.

Ministerio de Minas y Petróleos de Colombia. 1942. Compilación de los estudios geológicos oficiales en Colombia. Tomo V. Imprenta Nacional. Bogotá, 544p. 
Pérez, T.S. y Rodríguez, P.E. 1950. Selección de escritos y discursos de Santiago Pérez. Volumen 81 de la Biblioteca de Historia Nacional. Editorial Voluntad. Bogotá, 347p.

Pérez, F. 1862. Jeografía Física i Política de los Estados Unidos de Colombia. Imprenta de la Nación. Bogotá, $650 \mathrm{p}$.

Pérez, F. 1876. Compendio de Jeografía General de los Estados Unidos de Colombia. Imprenta Echeverría Hermanos. Bogotá, 98p.

Pérez, F. 1883. Geografía general física y política de los Estados Unidos de Colombia y geografía particular de la ciudad de Bogotá. Imprenta Echeverría Hermanos. Bogotá, 455p.

Pérez, F. 1888. Geografía general del Nuevo Mundo y en particular de cada uno de los países y colonias que lo componen. Casa Editorial de J. J. Pérez. Bogotá. p.114.

Pérez E., I., y Rosero C., I. 2013. Diseño de un centro turístico histórico-cultural en el sector de Tulcanquer como aporte al turismo de la ciudad de Tulcán. Universidad Politécnica Estatal del Carchi, 160p.

Ramírez, J.E. 1975. Historia de los Terremotos en Colombia. Instituto Geográfico Agustín Codazzi. Bogotá, 250p.

Reiss, W., y Stubel, A. 1873. Alturas tomadas en la República de Colombia en los años 1868 y 1869. Anales de la Universidad Nacional de los Estados Unidos de Colombia (1868-1875): 7 (5): 176-192. Consultado el 20 de noviembre de 2014. http://revistas.unal.edu.co/ index.php/analesun/article/view/13139/13807

Revista Credencial Historia. 2006. Colombia y el Mundo 1924. Edición 195. Consultado el 5 de diciembre de 2014. http://www.banrepcultural.org/blaavirtual/ evistas/credencial/marzo2006/mundo1924.htm

Rodríguez Guerrero, I., 1958. Estudios Geográficos del Departamento de Nariño. Imprenta departamento. Pasto. 557p.

Rosero, M.L. 1999. Autorretrato del Carchi. Realidad y fantasía ilustrada de la provincia. Gráficas SantiArt. Quito, 109p.

Rosero, M.L. 2006. Autorretrato del Carchi. Volumen II. Publioffset. Quito, 134p.
Ruiz, M., Gómez, D., Mothes, P., Torres, R., Sierra, D., Acero, W., Anzieta, J., Bernard, B., Cadena, O., Enríquez, W., Hernández, S., Hidalgo, S., and Pacheco, D. 2014. Unrest of Chiles - Cerro Negro volcanic complex: A binational Ecuador - Colombia effort. AGU Fall Meeting. San Francisco, Estados Unidos. https:// agu.confex.com/agu/fm14/meetingapp.cgi/Paper/19985

Sarabia, A., y Cifuentes, H. 2007. Estudio macrosísmico del sismo del 14 de diciembre de 1923 en Cumbal (Nariño). INGEOMINAS. Bogotá, 116p.

Sencial, U.B. 1908, Conferencias. Tipografía Sánchez y De Guise. Ciudad de Guatemala, 28p.

Servicio Geológico Colombiano. 2014. Informe Mensual de Actividad de los Volcanes Galeras, Cumbal, Doña Juana, Azufral, Las Ánimas y Chiles Cerro Negro, Octubre 2014. Consultado el 15 de diciembre de 2014. http://www.sgc.gov.co/getattachment/1a8c2cf8-20884709-b09d-fe72526ae0f1/Octubre-de-2014.aspx

Stübel, A. 1906. Die Vulkanberge von Colombia. Dresden Verlag von Wilhelm Baensch. Dresden, 154p.

Tapia, A., Monroy, J., y Martínez, E. 2011. Chical en la historia. Portal web del Gobierno Autónomo Descentralizado Parroquial Rural de Chical, Ecuador. Consultado el 10 de octubre de 2014. http://chical.gob. ec/carchi/?p=99

The Milwaukee Journal. 1936. Volcano Adds to Quake Ruin. Edición del 19 de julio de 1936. Consultado el 10 de octubre de 2014 .

http://news.google.com/newspapers?nid=1499\&dat=19 360719\&id=VbJQAAAAIBAJ\&sjid=AyIEAAAAIBA $\mathrm{J} \& p g=4947,7687254$

Torres, R., Cadena, O., Gómez, D., Ruiz, M., Prejean, S., Lyons, J., and White, R. 2015a. Intense seismic activity at Chiles and Cerro Negro volcanoes on ColombiaEcuador border. AGU Fall Meeting. San Francisco, Estados Unidos.

Torres, R., Cadena, O., Gómez, D., Ruiz, M., Prejean, S., Lyons, J., and White, R. 2015b. Seismic crisis at Chiles and Cerro Negro Volcanoes. Conferencia Anual 2015 de la Sociedad Sismológica de América (SSA).

Turchi, M.C. 2014. Perspectiva ideal de Túquerres. Consultado el 23 de noviembre de 2014. http://www. codazzi.mitreum.net/es/medida/cartografiacolombia.php 
Vergara, y Velazco, F.J., 1901. Nueva geografía de Colombia escrita por regiones naturales. Tomo I. Imprenta de vapor. Bogotá, 1.190p.

Villavicencio, M. 1858. Geografía de la República de Ecuador. Consultado el 20 de enero de 2016. https:// archive.org/details/geografiadelare00villgoog

Wolf, T. 1892. Geografía y geología del Ecuador. Tipografía de F. A. Brockhaus. Leipzig, 671p.

Trabajo recibido: diciembre 19 de 2014

Trabajo aceptado: agosto 26 de 2016

Manuscrito publicado en internet: septiembre 5 de 2016 